EPOS, XV (1999), págs. 113-126

\title{
ENTRE LA ETNOLINGÜÍSTICA Y LA LITERATURA: LA PALABRA, LA COSA Y LA PALABRA-SER*
}

\author{
Dora Sales Salvador \\ Universidad Jaume I de Castellón
}

La búsqueda de las palabras actuantes. Otra magia. El poeta y el escritor de verbo activo. La vida. Sus variaciones. Nada prefabricado. Todo en ebullición. No hacer literatura. No sustituir las cosas por palabras. Buscar las palabras-cosas, las palabras-seres. Miguel ÁnGel Asturias

\section{RESUMEN}

¿Es siempre arbitrario el signo lingüístico? Si atendemos a los postulados de Saussure diremos que sí. No obstante, otras voces desafían esta máxima linguiística asumida por la mayoría. Tras recorrer brevemente la huella del debate entre las palabras y las cosas a través de la lingüística y la filosofía del lenguaje, nuestra intención es plantear un acercamiento interdisciplinar, desde la literatura y la reflexión metadiscursiva, ante un tema que también contiene ricas posibilidades para la

* Mis más sinceros agradecimientos a Julio Calvo, por su siempre afectuosa e inestimable ayuda, y a Margarita Porcar, por los pacientes comentarios críticos. A ellos van dedicadas estas páginas. 
disciplina etnolingüística. Con este propósito, centraremos nuestras reflexiones en torno al discurso narrativo del escritor y antropólogo peruano José María Arguedas, bilingüe quechua-español. Para él, en quechua, la palabra era la cosa.

El propósito del presente trabajo parte de un enfoque eminentemente interdisciplinar en torno al estudio de la literatura, y más concretamente, de las que denominamos «narrativas de transculturación», aquéllas que ficcionalizan el complejo proceso de tránsito de una cultura a otra. En primer lugar, abordaremos el debate entre las palabras y las cosas desde la lingüística y la filosofía del lenguaje. Tras ello, centraremos nuestras consideraciones en la narrativa del escritor, antropólogo y etnólogo peruano José María Arguedas (1911-69), ejemplo paradigmático del proceso transculturador. Arguedas, inmerso en una compleja y dolorosa situación vital, a caballo entre el mundo indígena quechua en el que se crió y el mundo blanco al que pertenecía por nacimiento, fue bilingüe en quechua y en español. El autor manifestó siempre sus enormes dificultades para escribir en lengua castellana, pues era la indígena la que sentía como propia. Para él, en quechua, la palabra no era un signo arbitrario y convencional, sino que la palabra era la cosa. El pensamiento de Arguedas, reflejado por igual en sus escritos narrativos y antropológicos, remite a la relación entre lengua y cultura, objeto de estudio de la etnolingüística, y a la rica creación literaria de quien posee dos mundos, dos lenguas, dos culturas.

El DEBATE DE laS PALABRAS Y LAS COSAS

Ya en la Antiguiedad surge una problemática que durante siglos va a ocupar la atención de diversas generaciones de intelectuales, una cuestión que vertebra estas páginas y que Hans Arens plantea del siguiente modo: «si las palabras, las denominaciones, convienen a las cosas por naturaleza o sólo por una mera disposición, estatuto o convenio» (Arens, 1969 I: 19). Tal y como explica Georges Mounin (1967) este debate puede seguirse desde hace dos milenios y medio, desde antes de Platón hasta Descartes, Leibniz y Condillac, y desde ellos hasta Bréal y, obviamente, Saussure, pues, en definitiva, apunta a la teoría de la arbitrariedad del signo lingüístico.

Como explica Arens, el planteamiento que surge de esta cuestión alude al valor de verdad que contienen las palabras. Si las cosas reciben su nombre por naturaleza, atendiendo a su propia esencia, entonces las palabras serían verdaderas. Si, por el contrario, el nombre de las cosas no corresponde al ser de las 
mismas sino a una designación caprichosa, entonces las palabras carecerían de verdad.

Es seguramente en el pensamiento griego donde surge la problemática por primera vez. Un problema que, como resume Mounin (1967: 99), oponía por una parte, a los que creían que las palabras significan necesariamente por naturaleza ( $p h y s e i$ ), bien por su origen expresivo, bien por su estructura etimológica, la realidad que nombran; mientras, por otra parte, se situarían los que pensaban que las palabras nombran por convención (thései), por acuerdo (omologia) o por consenso (syndiké) entre los hombres. Platón es quien representa la primera de estas formulaciones, mientras Aristóteles se decanta por la segunda de ellas. No obstante, es posible que Platón sostenga su tesis con cierta dosis de ironía, al tiempo que tampoco se puede tratar de demostrar que Aristóteles preconice por completo las ideas de Saussure. Lo que ciertamente se puede afirmar es la existencia de dos argumentos contrapuestos entre sí: el argumento naturalista, centrado en la importancia de la onomatopeya y el simbolismo sonoro en la estructura fonológica de algunas palabras, y el argumento convencionalista, que intuye la posibilidad de cambio en el vocabulario.

En el diálogo de Platón (427-347 a.C.) Cratilo o de la exactitud de las palabras ', el pensador griego dice que únicamente a partir de la forma primitiva de la palabra se podría deducir el significado apropiado. En definitiva, el tema de este diálogo es el debate sobre el origen del lenguaje y las relaciones entre las palabras y sus significados. Cratilo opina que para cada cosa hay un nombre que surge de la naturaleza de la cosa misma. De igual modo pensará Sócrates. Contrariamente a Cratilo, Hermógenes no se convence de que el nombre estribe en otra cosa que no sea el acuerdo y la convención. Finalmente, Sócrates argumenta ante Cratilo que hay que admitir la contribución de la convención y el uso a la representación de lo que pensamos al hablar. Robins (1967) opina que en el texto no se llega a una conclusión definitiva. Ciertamente, no se admite por completo la afirmación de Hermógenes acerca de que todos los nombres son fruto de una simple convención, aunque tampoco se admite la posición de Cratilo sobre la exactitud natural completa.

Tras Platón, los pensadores fueron adoptando una postura más claramente definida. Así, Aristóteles optó finalmente por un punto de vista convencionalista. En su opinión, el lenguaje se rige por el acuerdo. Epicuro se situó en una posición intermedia, con la idea de que las formas de las palabras surgen

' En la realización del presente trabajo, hemos consultado la edición de Cratilo incluida en las Obras completas de Platón. Véase Platón (1972). Como afirma Francisco de P. Samaranch en su prólogo, el texto no contiene ninguna indicación ni acerca del momento en el que tiene lugar el diálogo, ni acerca de la época de su composición. 
de manera natural, pero se modifican por convención. Los Estoicos, apoyándose de nuevo en la onomatopeya y el simbolismo sonoro, se decantaron por el estatus natural del lenguaje. La problemática ya planteada por los griegos, se resume, en definitiva, como analogía versus convención. En este orden de cosas, coincidimos con Robins en que el planteamiento del debate en el seno del pensamiento griego no supone sino un interesante inicio abierto a la futuridad:

In maintaining and in criticizing each side of the argument people were led to examine more closely the structures and the meanings of words and the formal patterns that words exhibited. In such examinations lies the beginning of precise linguistic analysis (RoBINS, 1967: 22).

Tiempo después, durante la época de la Ilustración, Francis Bacon (15611626) publicó, en 1623, un inventario titulado De dignitate et augmentis scientiarum, en el que distingue una «grammatica literaria» y una "philosophica». La primera de ellas es la corriente que sólo se ocupa de las palabras y sus mutuas analogías, mientras la segunda se ocupa de la analogía entre palabra y cosa.

Como afirma Mounin (1967), el problema central en los tiempos modernos siempre es el de la relación del lenguaje con el pensamiento, pues los filósofos como Bacon, Descartes, Hobbes, Spinoza, Locke y Leibniz, conciben el lenguaje como el medio de expresión del pensamiento. De hecho, John Locke (1632-1704) contribuye a la filosofía del lenguaje con su Essay concerning $\mathrm{Hu}$ man Understanding, donde estudia, entre otras muchas cosas, la naturaleza y función de la palabra, llegando a trazar una clara línea separatoria entre la palabra y la cosa. Formulando lo que Saussure postulará claramente muchos años después, Locke llega a afirmar que una palabra no es más que un signo cuyo sentido es "perfectamente arbitrario».

Quien también formula ya en los tiempos modernos una clara teoría sobre la arbitrariedad del signo es Condillac (1714-1780), especialmente en su Essai sur l'origine des connaissances humaines (1746), en el que postula que los signos de las lenguas son signos «de institución" ${ }^{2}$, que escogemos nosotros mismos y que tienen con nuestras ideas una relación únicamente arbitraria.

El geógrafo e historiador Charles de Brosses (1709-1777) en su Tratado de la formación mecánica de las lenguas y los fundamentos físicos de la etimología (1765), afirma la existencia de la correspondencia entre el objeto A, la percepción de A, y la expresión para denominar A. Así, de nuevo, nos remontamos al Cratilo, donde también se postulaba la idea de que las palabras imitan a las cosas. Sin embargo, Arens piensa que mientras Platón restringía este

2 Término que procede de Aristóteles. 
principio, o incluso lo negaba, De Brosses sólo lo aplica a las palabras que le resultan apropiadas para la demostración. Con todo, como afirma Mounin (1967: 157):

No hay que subestimar la importancia de estas teorías de fines del siglo XVIII sobre la lingüística que resurge con Saussure. Bréal, a quien Saussure ha prestado atención, se había inspirado en Condillac, a quien se refiere explícitamente, deplorando que se haya rechazado su enseñanza sobre el signo.

Queda claro, pues, que el rico y manido debate de las palabras y las cosas, que nace en la Antigüedad, fundamentalmente en el entorno del pensamiento griego, supone un estímulo constante a modo de reflexión sobre el lenguaje humano, ocupando un lugar destacado en los postulados de filósofos y escolásticos hasta Saussure, con quien el tema retorna a la disciplina lingüística. Y es que Saussure, inaugurando la linguiística del presente siglo, traza una firme línea divisoria entre las palabras y las cosas al definir el signo lingüístico como arbitrario, unión de un significante (imagen acústica) y un significado (concepto). En sus propias palabras:

Lo que el signo lingüístico une no es una cosa y un nombre, sino un concepto y una imagen acústica (...) El lazo que une el significante al significado es arbitrario; o bien, puesto que entendemos por signo el total resultante de la asociación de un significante con un significado. podemos decir más simplemente: el signo lingüístico es arbitrario (SAUSSURE, 1972: 88-90).

El propio Saussure puntualiza que por «arbitrario» quiere decir «inmotivado», arbitrario con respecto al significado, con el que no está unido por ningún tipo de lazo natural. Aunque él mismo señala que su teoría podría ser objetada por la existencia de las onomatopeyas y las exclamaciones, concluye que son de importancia secundaria en el lenguaje, y que su origen simbólico puede plantear dudas. Por otra parte, y como nos recuerda Mounin (1972: 55), Saussure también afirma que la lengua es forma, pero no sustancia.

En el marco de la lingüística más moderna, el debate de las palabras y las cosas resultaría interesante desde la disciplina de la etnolinguística, cuyo objeto de estudio resume Casado Velarde (1988: 39) del siguiente modo: «se suele considerar como objeto de la etnolinguística 'el aspecto cultural del uso de la lengua', o incluso, 'el aspecto antropológico de la lengua'». La etnolinguística atiende, en definitiva, a las relaciones entre lengua y cultura, sin olvidar el pensamiento propio de cada sistema cultural. Creemos que, en el caso que nos 
ocupará en la segunda parte de nuestro trabajo, nos referimos a la lengua como expresión de una cultura, lo que entra en el ámbito de la etnografía lingüística. Las relaciones lengua-cultura, también se hallan, no obstante, en la base de la geografía lingüística, próxima al movimiento denominado precisamente Wörter und Sachen (palabras y cosas). Como nos dice Casado Velarde (1988: 25), «la 'geografía linguiística' designa un método dialectológico y comparativo que presupone el registro en mapas especiales ${ }^{3}$ de un número relativamente elevado de formas linguíísticas (fónicas, léxicas y gramaticales) comprobadas mediante encuesta directa y unitaria en una red de puntos de un territorio determinado". En definitiva, esta disciplina se ocupa de la extensión y distribución espacial de fenómenos lingüísticos particulares. Como explica Manuel Alvar (1973), la sociología fue centro de preocupaciones en estos estudios, potenciados por Gilliéron y Jaberg, entre otros lingüistas. Algunos resultados derivados de estos análisis han sido de interés en investigaciones etnográficas y folklóricas. Gilliéron consideraba de importancia la relación entre las palabras y la vida material de los hablantes: las cosas que las palabras designan. Como concluye Casado Velarde (1988), el método geográfico ha sido esencial para demostrar que los cambios lingüísticos se difunden por motivos socio-culturales, pues las palabras son formas de cultura que verbalizan conceptos y objetos de civilización. Esto nos hace pensar en la teoría del reflejo de Schaff, que recuerda Karmele Rotaetxte (1990: 92-93). Según esta teoría, la lengua será reflejo y no copia, sistema que no impone la visión de la realidad, aunque sí la moldea a través de la organización sociocultural. Sucede, en palabras de Helios Jaime Ramírez (1997), que «no hay signo lingüístico que no vaya unido a la noción de contexto».

Por otra parte, respecto a la interrelación entre lenguaje y cultura, tendríamos que aludir también a las concepciones en torno a las relaciones entre lengua y pensamiento, que adoptan, en ocasiones, posiciones extremadas. Las ideas vosslerianas y la «hipótesis Sapir-Whorf» son el caso más radicalizado. De hecho, esta hipótesis refleja una visión extrema de la cuestión de la relatividad cultural, pues llega a proponer que los hablantes de lenguas diferentes viven en mundos distintos, es decir, que la lengua impone de alguna manera sus patrones al pensamiento. Como nos recuerda Casado Velarde (1988), tanto Vossler como Sapir y Whorf se basan en Humboldt, quien opinaba que las relaciones entre lengua y mentalidad adoptan una forma de mutua interacción. Sin embargo, lo cierto es que, partiendo de los planteamientos humboldianos, Whorf, tras sus trabajos con los hopis, los extrema al formular el principio de la «relatividad lingüística», según el cual el lenguaje determina el pensamiento. Como

\footnotetext{
${ }^{3}$ Mapas que Manuel Alvar (1973) denomina «atlas etnográficos».
} 
resume Ángel López (1988: 133): «Probablemente lo que estamos necesitando es un modelo capaz de conjugar la coincidencia y la divergencia entre el mundo verbal, el mundo mental y el mundo real al mismo tiempo».

Con todo, seguramente la reflexión más amplia en torno a la relación entre las cosas y las palabras que las nombran es la que nos ofrece el filósofo francés Michel Foucault (1966) en Las palabras y las cosas. Una arqueología de las ciencias humanas. En este ensayo denso y sagaz se ataca a todas esas historias sobre la representación realista que han tratado de explicar la auténtica naturaleza de la relación entre las palabras y las cosas. En apariencia, Las palabras y las cosas se presenta como una historia de las ideas, pero sabemos que el propio Foucault niega su intención de escribir una historia del tipo convencional. De hecho, él, historiador antihistórico, propone hablar de «arqueología» en vez de «historia», pues su interés radica, más bien, en las rupturas, las disrupciones y las discontinuidades.

Opina Foucault que todo el esfuerzo de la representación deviene de un mal entendimiento de la naturaleza del lenguaje. Atendiendo fundamentalmente a la cuestión de la representación, la palabra como representante de la cosa nombrada, Foucault argumenta que la separación entre las palabras y las cosas, que sí se da en el discurso, desde la época clásica, se desvanece en la literatura. En ella, el ser dividido del lenguaje se recompone, haciendo que reaparezca el ser vivo de las palabras:

La literatura es la impugnación de la fílología (de la cual es, sin embargo, la figura gemela): remite el lenguaje de la gramática al poder desnudo de hablar y ahí encuentra el ser salvaje e imperioso de las palabras (FouCAULT, 1966: 293).

Desde la renovadora disciplina de la crítica cultural, Hayden White (1978) piensa que la fundamentación última de Las palabras y las cosas es correcta e iluminadora: tal y como se han desarrollado entre los siglos XVI y XX, las ciencias humanas se han caracterizado por su incapacidad para reconocer hasta qué punto son prisioneras del lenguaje mismo. Su error principal ha sido no contemplar con claridad la problemática que late en el lenguaje. Foucault, como Lacan desde el psicoanálisis y Lévi-Strauss desde la etnología ${ }^{4}$, propone su propia concepción de lo que es la ciencia humana. Una ciencia, en última instancia, poética. Como concluye White (1978: 259):

${ }^{4}$ Se ha querido ver en Foucault al filósofo del estructuralismo francés, comparándolo con Lévi-Strauss en etnología y Lacan en psicoanálisis. Sin embargo, el propio Foucault ha negado cualquier tipo de filiación con este movimiento. Lo que sí es cierto, diremos, es que Foucault, Lévi-Strauss y 
To transform prose into poetry is Foucault's purpose, and thus he is especially interested in showing how all systems of thought in the human sciences can be seen as little more than terminological formalizations of poetic closures with the world of words, rather than with the «things» they purport to represent and explain.

Foucault, desde la reflexión profunda, sabe que en el discurso las cosas y las palabras se separan, deshaciendo la pertenencia del lenguaje y del mundo: «El discurso tendrá desde luego como tarea el decir lo que es, pero no será más que lo que dice» (Foucault, 1966: 50). En la literatura, sin embargo, las palabras adquieren vida, son vida. El propósito de cargar a la palabra con la materia de las cosas desafía de frente las teorías sobre la arbitrariedad del signo, recordándonos que: «Hablar o escribir es (...) ir, a través del lenguaje, justo hasta el lugar en el que las cosas y las palabras se anudan en su esencia común y que permite darles un nombre» (Foucault, 1966: 122-23).

\section{La palabra y la materia de las cosas en la NARRativa de José María ARGUEDAS}

Para Arguedas, las palabras no son signos arbitrarios y convencionales (cuestiones centrales de la lingüística a partir de Saussure), en las que cabe separar, sin más, el significante (cuerpo sensorial del lenguaje: acústico, gráfico, etc.) del significado, y éste, en tanto que constituye una representación mental de la cosa, y no la cosa misma, del referente, es decir, las cosas en la medida en que son mencionables dentro de las redes de representación del mundo propias del lenguaje de una cultura determinada. Por contra, Arguedas piensa que el significante resulta «motivado»: brota del contexto vital de una comunidad lingüística, como una respuesta natural, propia de la cultura, a las vivencias que dicha comunidad tiene con las cosas mismas, puesto que de esas vivencias nacen lo que los linguiistas llaman significados y referentes. El realismo narrativo de Arguedas se apoya, precisamente, en la confianza en el lenguaje como expresión de la realidad, lo que podríamos denominar un «realismo lingüístico».

Lacan comparten el interés por las estructuras profundas de la conciencia humana, así como la convicción de que el estudio de dichas estructuras debe comenzar con un análisis del lenguaje. Recordemos, también, que su concepción del lenguaje tiene origen en los trabajos de Saussure, padre de la lingüística estructural. Al tiempo, los tres coinciden en que la disociación entre lenguaje y pensamiento humano debe disolverse, como primer paso para poder entender los fenómenos humanos como elementos de un sistema de comunicación. 
Sucede, como nos recuerda Roland Forgues (1989), que para Arguedas las palabras no son solamente el nombre de las cosas, sino, sobre todo, el reflejo de las ideas. La unión entre el objeto y la idea es el fundamento mismo de la escritura arguediana, pues el realismo que defiende no se articula únicamente sobre la relación del nombre, del significante y de su referente, sino también, y esencialmente, sobre las relaciones del significado y del significante, o sea, sobre el signo. El propio Arguedas llegó a afirmar en el Primer Encuentro de Narradores Peruanos, celebrado en Arequipa en 1965:

La palabra es nombre de cosas o de pensamientos o de reflexiones que provienen de las cosas, de lo que se piensa sobre las cosas; lo que es realidad verbal es realidad realidad (...) Tampoco hay palabras que puedan inventar realidades, la palabra sólo es un reflejo de la cosa que existe» (Citado en ForGues, 1989: 55).

Con todo, contrariamente a lo que ha afirmado la lingüística moderna después de Ferdinand de Saussure y su Curso de lingüística general, existe para José María Arguedas, por lo menos en la lengua quechua, una relación motivada entre el significante y el significado, con lo que problematiza el principio de la arbitrariedad del signo linguístico, formulado por Saussure. La convicción de que los signos verbales del quechua son «motivados» no surge únicamente de la conciencia bilingüe y bicultural de Arguedas, sino que ya forma parte del ancestral patrimonio cultural quechua. Como nos recuerda Martin Lienhard (1981), ya hay afirmaciones al respecto en Dioses y hombres de Huarochirí, tradicional narración quechua que el propio Arguedas tradujo en 1966.

Es esta relación motivada la que le sirve a Arguedas para elaborar su propia escritura. Pensamos que el ejemplo más paradigmático y clarificador es el acercamiento fonético y semántico al concepto de zumbayllu, en la novela $L o s$ ríos profundos (1958), que contiene la idea de luz, sonido y movimiento como elementos que se fusionan estrechamente en el enunciado ${ }^{5}$. El autor concibió su narrativa como un exacto diagrama verbal de una realidad cuya potencia nunca puso en duda: así era la realidad y así exactamente la decían las palabras.

El crítico uruguayo Ángel Rama (1982) se encarga de recordarnos que en las comunidades ágrafas, como la andina, la palabra es un instrumento privilegiado de elaboración y transmisión cultural, empleado con la reverencia y

Reproduciremos un fragmento de este ejemplo más adelante, al aludir a la cuestión ono- 
laconismo de un valor superior, reconociéndosele cierta capacidad encantatoria o poder sobrenatural. A este respecto, no hay que olvidar que las reflexiones de Arguedas se centran en la lengua quechua. Sin embargo, pese a que casi todas las observaciones linguísticas se refieran al idioma indígena, lo cierto es que fue la lengua española la que le sirvió al autor como punto de referencia para detectar las singularidades del quechua. Es en su percepción de la diferencia donde el autor analiza una situación comunicativa de desgarro existencial. El quechua, para Arguedas, se presenta como la lengua materna, circundada de asociaciones afectivas, dotada de rica polisemia. El español, por contra, es el idioma aprendido, aquél en el que el sujeto se ve obligado a comunicarse. En el esfuerzo por hacer suyo el lenguaje de la conquista, Arguedas siente que la intimidad entre las palabras y las cosas quechuas se le torna abismo.

En este punto, nos parecen interesantes las reflexiones de Ángel Rama con respecto a la fuerza asociativa que conservan las palabras de la lengua de la infancia: el quechua, en el caso de Arguedas. Rama (1982: 242-46) considera tres rasgos que resumimos en lo que sigue:

a) Esas palabras siguen trabajando sobre un sistema analógico que atiende a cualidades como los fonemas que las integran, que desde la perspectiva adulta podrían considerarse como cualidades secundarias, pero que en la infancia son primarias.

b) El universo infantil percibe más intensamente la energía de las palabras. Piensa Rama que esto se debe a que reconoce en ellas la presencia de la cosa referida.

c) La tercera vinculación entre la palabra y la cosa sería de naturaleza metonímica, apuntando a la idea de que la palabra conlleva el entorno, múltiple, donde fue emitida: «Funciona como un punto focal, un aleph, que absorbe un variado abanico de datos o imágenes» (Rama, 1982: 246). En este sentido, el ensayista y poeta mexicano Octavio Paz también llega a la conclusión de que en el lenguaje infantil las palabras y las cosas que éstas nombran funden una misma realidad:

El lenguaje, desnudo de sus significaciones intelectuales, deja de ser un conjunto de signos y vuelve a ser un delicado organismo de imantación mágica. No hay distancia entre el nombre y la cosa y pronunciar una palabra es poner en movimiento a la realidad que designa (...) Hablar vuelve a ser una actividad creadora de realidades, esto es, una actividad poética. El niño, por virtud de la magia, crea un mundo a su imagen y resuelve así su soledad. Vuelve a ser uno con su ambiente (PAZ, 1950: 350). 
En esta capacidad evocativa, la palabra se hermana con la música. Y no hay que olvidar que el propio Arguedas afirmó, en su ficción ${ }^{6}$, que el canto de las calandrias era seguramente la materia de la que estaba hecho: ser, lenguaje, mundo. Lo fundamental es recordar que, en la conciencia del autor, la palabra no es escritura sino sonido vivo, sonido real.

Desde esta perspectiva fónica, resulta interesante y clarificador tener en cuenta las cualidades onomatopéyicas del quechua, que Arguedas enfatizaba como una de las características principales de esta lengua amerindia, en un intento por demostrar la relación entre el quechua como sistema expresivo y la experiencia de la realidad. Como nos recuerda William Rowe (1979), la primera referencia a la onomatopeya aparece en un artículo que Arguedas publica en 1948, titulado «La literatura quechua en el Perú». En él, el autor afirma que «en el quechua, muchos términos están sumergidos en los objetos, gracias a la supervivencia (...) de la onomatopeya» (Citado en Rowe, 1979: 103). El contexto de esta afirmación remite al problema de la traducción, en una época en la que Arguedas ya había empezado a escribir Los ríos profundos (1958), novela en la que se considerará que la naturaleza onomatopéyica del quechua deriva del hecho de que esta lengua refleja la interrelación hombre-naturaleza. Arguedas expresó esta idea en numerosos lugares, pero aquí destacamos el modo en el que lo afirmó en la introducción de Tupac Amaru kamaq taytanchisman (haylli-taki)/A nuestro padre creador Tupac Amaru (himno-canción) (1962):

Palabras del quechua contienen con una densidad y vida incomparables la materia del hombre y de la naturaleza y el vínculo intenso que por fortuna aún existe entre lo uno y lo otro. El indígena peruano está abrigado, consolado, iluminado, bendecido por la naturaleza: su odio y su amor, cuando son desencadenados, se precipitan, por eso, con toda esa materia, y también su lenguaje (ARGUEDAS, 1984: 59).

También en el prólogo que escribió para Yawar fiesta en 1968 habla del «onomatopéyico quechua que contiene en sus sílabas casi la esencia material de las cosas y el modo cómo en esas materias el hombre se ha derramado para siempre» (Arguedas, 1980: 6). En todas estas afirmaciones, la palabra clave es "materia», pues se sugiere que hay algún tipo de vínculo material, real, entre el sonido de las palabras y sus referentes, la enunciación y lo enunciado. Si aceptamos los principios de lingüística de Saussure, resulta imposible esta conexión encarnada entre los elementos fonéticos y semánticos del lenguaje, ya que las palabras son signos arbitrarios. No obstante, como Rowe (1979: 104),

' Concretamente, a través de Emesto, el narrador-protagonista de Los rós profundos. 
pensamos que «sería erróneo concluir que Arguedas ha creado una simple ilusión. Existe un sentido en el que los sonidos están ligados a los significados, aunque no de una manera apriorística.» $A$ este respecto, resultan interesantes las ideas expuestas por Claude Lévi-Strauss (1958) en el marco de su Antropología estructural, concebida como una teoría general de las relaciones, donde el antropólogo francés discute el principio de la arbitrariedad del signo linguiístico formulado por Saussure. Lévi-Strauss afirma que el principio saussuriano resulta inobjetable desde el nivel de la pura descripción lingüística, pero en su opinión, el signo lingüístico, que sí es arbitrario a priori, deja de serlo a posterio$r i$, tanto en el nivel fonético como en el de vocabulario, con lo que el carácter arbitrario del signo resultaría, en sus propias palabras, «provisional»:

Cuando consideramos el vocabulario a posteriori, es decir ya constituido, las palabras pierden mucho de su carácter arbitrario, porque el sentido que les atribuimos no es ya solamente función de una convención. Depende de la manera en que cada lengua compartimente el universo de significación del cual la palabra forma parte, es función de la presencia o de la ausencia de otras palabras para expresar sentidos vecinos (...) La elección del signo puede ser arbitraria, pero éste conserva, con todo, un valor propio, un contenido independiente, que se combina con la función significante para modularla (LÉvi-STRAUSS, 1958: 132-133).

De este modo, la concepción arguediana conllevaría la idea de que dentro de un sistema cultural determinado, que organiza los significados atendiendo a ciertos principios, las palabras y las cosas deshacen, en gran medida, la posible arbitrariedad que las haya unido. Con todo, creemos que la disciplina desde la que resultaría interesante abordar este planteamiento sería la de la etnolinguíística.

Rowe (1979) afirma que lo ilusorio en las fundamentaciones de Arguedas es la teoría que invocan, y no las cualidades del quechua que el autor trata de definir, que en opinión del crítico son sumamente ilustrativas. Sin embargo, no piensa igual Rama (1982), para quien los ejemplos onomatopéyicos, en la posición extrema de la convicción arguediana, no son privativos del quechua. El crítico uruguayo considera como "presunto" el carácter onomatopéyico de la lengua quechua, acentuado por Arguedas, y cree que el ejemplo del zumbayllu no lo prueba por completo, recordando, además, que las onomatopeyas de los cantos de los mismos animales tienen distintas transcripciones fonéticas en las diversas lenguas. A continuación, reproducimos uno de los fragmentos que Arguedas dedica, en el capítulo «Zumbayllu» de la novela Los ríos profundos, a las terminaciones quechuas yllu e illa, para tratar de contemplar, sobre el texto, toda esta problemática: 
La terminación quechua yllu es una onomatopeya. Yllu representa en una de sus formas la música que producen las pequeñas alas en vuelo; música que surge del movimiento de objetos leves. Esta voz tiene semejanza con otra más vasta: illa. Illa nombra a cierta especie de luz y a los monstruos que nacieron heridos por los rayos de la luna. Illa es un niño de dos cabezas o un becerro que nace decapitado; o un peñasco gigante, todo negro y lúcido, cuya superficie apareciera cruzada por una vena ancha de roca blanca, de opaca luz; es también illa una mazorca cuyas hileras de maíz se entrecruzan o forman remolinos; son illas los toros míticos que habitan el fondo de los lagos solitarios, de las altas lagunas rodeadas de totora, pobladas de patos negros. Todos los illas, causan el bien o el mal, pero siempre en grado sumo. Tocar un illa, y morir o alcanzar la resurrección, es posible. Esta voz illa tiene parentesco fonético y una cierta comunidad de sentido con la terminación yllu (ARGUEDAS, 1958: 72).

En este pasaje se observa el proceso por el cual, mediante la elaboración de un sistema cultural concreto, los fonemas se vuelven simbólicos. El sonido illa se convierte en portador de las correspondencias entre los distintos significados, asociados por un pensamiento de arraigadas connotaciones mágico-religiosas o míticas, en consonancia con lo postulado por Lévi-Strauss (1962) ${ }^{7}$. Obviamente, estas interrelaciones no devienen de las propiedades estrictamente linguísticas del quechua como lengua sino de la mediación de un sistema cultural, el indígena, que considera la naturaleza como un mundo lleno de mensajes, un entorno semiótico que tiene su propia voz.

El elemento fonético que parece servir como unión entre la palabra y la cosa es, en realidad, un elemento semántico, de acuerdo a las asociaciones que elabora un pensamiento de cariz mítico. Así, como explica Rowe de manera concisa, la significación en el quechua, tal y como refleja Arguedas, deviene de la asociación entre las propiedades físicas y las semánticas, que parece propiciar el lazo entre sonido y significado, cuando lo que existe verdaderamente es un vínculo entre naturaleza y significado. Con todo, lo que sucede en el nivel linguístico refleja la estructura del pensamiento, haciendo que Arguedas hable de los términos quechuas como si encarnasen la materia de lo dicho.

En este sentido, diremos que para Arguedas la palabra no es objetivamente transparente sino que significa sólo cuando una subjetividad enunciadora, y no las cosas mismas, establece un vínculo entre la palabra y el mundo que ésta

7 En El pensamiento salvaje, LÉVI-STRAUSS (1962) explica cómo para la mentalidad mágicoreligiosa la naturaleza es reflejo de la realidad, y cómo, a través de la observación de la naturaleza, las relaciones entre los hombres se definen y controlan. 
nombra. En este orden de cosas, el referente que otorga realidad a la palabra es el yo: la subjetividad individual es la que aporta a la palabra sus connotaciones, al sentirla le otorga existencia, la «materializa». Sara Castro-Klarén (1989: 103), en un estupendo artículo sobre la problemática cuestión del bilingüismo en Arguedas y su relación con el lenguaje, el referente y la realidad, resume este planteamiento del siguiente modo: «El poeta es quien al sentir las cosas, e intervenir entre el mundo y la palabra, al nombrar las cosas, les infunde vitalidad, coincidencia con su propio ser» ${ }^{8}$.

En definitiva, para Arguedas el ser, el universo y la lengua forman una sola unidad. En varios textos, y con diversos matices, el autor expresó esta convicción de que el quechua está ligado a la vida subjetiva y a la realidad objetiva del entorno andino. Arguedas concibe una tríada entre ser, universo y lengua, lo que implica conferirle al lenguaje un puesto de igual importancia que el del sujeto y el objeto. En su expresión extrema, llegó a hablar de un enlace material. En el «Primer Diario» de El zorro de arriba y el zorro de abajo (1971, póstuma), el autor se identifica con un grupo de escritores, entre los que nombra a Joao Guimarâes Rosa, Juan Rulfo y Gabriel García Márquez, caracterizados por su capacidad de transmitir a la palabra la materia de las cosas. En última instancia, esta fundamentación arguediana remite, esencialmente, al conflicto entre lo oral y lo escrito, problemática que vertebra toda la obra de Arguedas. Y es que, para él, la esfera oral del quechua fue el lugar donde el signo verbal y la realidad fundían sus pieles en una.

Julio Calvo, especialista en lengua quechua, nos dice que toda lengua primitiva, no en el sentido de imperfecta sino como lengua oral, tiene más onomatopeyas que las lenguas abstractas de Occidente. Por ello, en su Introducción a la lengua y cultura quechuas, Calvo (1995: 31) afirma que «(..) en muchos casos hay cierta identidad entre el mundo y la lengua, por lo que el signo, pese a su asimetría, es ciertamente motivado y establece dependencias icónicas con el contexto.» A este respecto, el autor nos explica que este iconismo del signo, pese a su simbolismo y arbitrariedad, hace que las lenguas, no sólo el quechua, actúen motivadamente, tal y como se desprende de la morfología natural de Dressler y la lingüística cognitiva de la escuela de California ${ }^{9}$.

Por otra parte, el supuesto privilegio del idioma quechua, que Arguedas asentaba fundamentalmente en su naturaleza onomatopéyica, ha sido problematizado

* Esta posición, en la que enmarcamos el planteamiento enunciativo de Arguedas, contrasta con la expuesta por OCTAvio PAZ en El Mono Gramático: «El poeta no es el que nombra las cosas, sino el que disuelve sus nombres, el que descubre que las cosas no tienen nombre y que los nombres con que las llamamos no son suyos" (PAZ, 1974: 92).

'Comunicación personal, 11 de mayo de 1998. 
por cierto sector de la crítica. Recordemos, por ejemplo, la opinión de Ángel Rama (1982). También Martin Lienhard (1981) considera difícil admitir que el fonetismo quechua esté basado esencialmente en el mecanismo onomatopéyico, y que el fenómeno de la relativa arbitrariedad del signo deje de ser válido en este idioma. Sin embargo, afirma:

Se puede sostener, en cambio, que el quechua es un idioma que presenta en sus signos un mayor grado de «motivación». En efecto, en la clasificación de Saussure que divide los idiomas en «gramaticales» y «lexicológicos», el quechua (que no se menciona) sería un idioma «ultragramatical», puesto que fuera de las «raíces» relativamente poco numerosas (algunas de las cuales son, además, de origen onomatopéyico), todas las partículas aglutinantes con sus múltiples significados son perfectamente analizables, es decir, «motivados». El castellano, aun siendo un idioma mucho más «gramatical» que el chino (caso extremo de idioma «lexicológico»), tiene un grado de «lexicalización»-de arbitrariedad—, mucho más elevado que el quechua (LIENHARD, 1981: 66).

En definitiva, diremos, la escritura arguediana sueña con ser voz que quiebre toda escisión del signo en significante y significado. Un sueño que también comparten otros autores en el marco de las narrativas de transculturación en América Latina. Así, por ejemplo, dice el escritor paraguayo Augusto Roa Bastos, bilingüe en español y guaraní:

Tendría que haber en nuestro lenguaje palabras que tengan voz. Espacio libre. Su propia memoria. Palabras que subsistan solas, que lleven el lugar consigo. Un lugar. Su lugar. Su propia materia. Un espacio donde esa palabra suceda igual que un hecho (ROA BASTOS, 1974: 14).

Pese a lo utópico de una escritura así, Arguedas, como muchos otros autores transculturales, siente como real esa posibilidad de «materializar» la palabra. Y es que cuando el sujeto, en un entorno multicultural y polifónico, lucha por resolver la complejidad comunicativa y existencial en la que se halla - para tratar de comprender el mundo que le rodea-, la realidad y el lenguaje guardan una íntima relación identitaria. El mundo real tiene que pasar por el signo verbal, la enunciación del sujeto, para poder ser aprehendido. En este orden de lo simbólico, como diría Lacan $(1966)^{10}$, en este encuentro entre el decir y lo dicho, el ser trata de hallar, nombrar, su esencia.

10 Recordamos, en este punto, la tríada lacaniana de lo real, lo imaginario y lo simbólico. Lo real es lo que no pasa por el lenguaje, es decir, lo psicótico, lo que permanece en el nombre. Lo imaginario 
Podríamos concluir que todo el lenguaje narrativo arguediano viene a girar, en realidad, en torno a la relación motivada entre el significante y el significado. Una relación sin la cual la búsqueda de la universalidad a partir de lo propio hubiera resultado profundamente problemática, hasta quizá imposible. En esencia, como dice Ángel Rama (1982: 235), «para él [Arguedas], como raigalmente para la mayoría de los poetas, la palabra era la cosa, no meramente su significado representado en un sonido». De hecho, estéticamente, desde la poesía, se puede justificar que la palabra sea la cosa, si pensamos en la lengua poética como medio de creación de sentimientos intangibles, que crea el poeta al hablar o al escribir. Realidades que aparentemente no existen hasta que no son nombradas. El lenguaje artístico sirve para reflejar tales realidades. Recordemos que ya Foucault (1966), tras su extensa reflexión, concluye que el hiato entre las palabras y las cosas desaparece en la literatura. En ella, el nombre es la cosa que el nombre nombra, pues de otro modo esa cosa no existe en el mundo real. El poeta, al verbalizar sus emociones y su visión del mundo, crea nombrando, nombra creando ". Y es entonces cuando podríamos decir que las palabras sí son las cosas, las palabras-seres, las que le devuelven al lenguaje su ser vivo, y sus alas.

\section{BIBLIOGRAFIA}

Alvar, MANuel (1973): Estructuralismo, geografía lingüística y dialectología actual. Madrid: Gredos, 2. ${ }^{\mathrm{a}}$ ed. ampliada.

ARENS, Hans (1969): La lingüística. Sus textos y su evolución desde la antigüedad hasta nuestros días. José María Díaz-Regañón López (trad.) 2 vol. Madrid: Gredos, 1976, 2." ed.

ARguedas, José María (1958): Los ríos profundos. Madrid: Alianza, 1992.

es del orden de la identificación, de modo que el yo siempre remite a lo imaginario. Lo simbólico es la vertiente del lenguaje, de la palabra. Y es precisamente el orden de lo simbólico el que inscribe al hombre en lo real, en una estructura social y cultural. Por otra parte, para Lacan, no lo olvidemos, el significante tiene primacía sobre el significado, y adquiere sentido gracias a la cadena de significantes de la que forma parte.

"En el contexto de la poesía latinoamericana de este último siglo, sería interesante recordar la obra de autores tan distintos entre sí como Vicente Huidobro (Chile), interesado en la creatividad verbal y en la palabra que, liberada de su instrumentalidad, asume propiedades mágicas; Octavio Paz (México), para quien la poesía no significa dominar las palabras sino devolverles su esencia primitiva, y, fundamentalmente, César Vallejo (Penú), esencial punto de referencia en la literatura del propio Arguedas. Para Vallejo, el nombre no es suficiente para designar el objeto, pues la palabra no abarca la total realidad de la cosa. Por ello, en su poesía, Vallejo disloca el lenguaje, nombrando y desnombrando, para expresar su habla verdaderamente emotiva y encarnada. 
- (1962): Tupac Amaru kamaq taytanchisman (haylli-taki)/A nuestro padre creador Tupac Amaru (himno-canción), en Katatay/Temblar. Edición bilingüe. Lima: Horizonte, 1984, pp. 9-19.

- (1971, póstuma): El zorro de arriba y el zorro de abajo. Edición Crítica. EveMarie Fell (coord.) Madrid: CSIC. Colección Archivos, 14, 1990.

- (1980): Yawar fiesta (fiesta de sangre). Lima, Horizonte.

- (1984): Katatay/Temblar. Edición bilingüe. Lima: Horizonte.

AstuRIAS, Miguel ÁNGEL (1968): Latinoamérica y otros ensayos. Madrid: Guadiana de Publicaciones.

Calvo, Julıo (1995): Introducción a la lengua y cultura quechuas. València: Universitat de València, Departament de Teoria dels Llenguatges. De acá para allá: Lenguas y Culturas Amerindias, núm. 1.

Casado Velarde, Manuel (1988): Lenguaje y Cultura. La Etnolingüística. Madrid: Síntesis, Colección Linguística, núm. 16.

Castro-Klarén, Sara (1989): «Mundo y palabra: Hacia una problemática del bilingüismo en Arguedas», en Escritura, transgresión y sujeto en la literatura latinoamericana. Tlahuapan, Puebla: Premià, pp. 97-105.

De Saussure, Ferdinand (1972): Curso de Lingüística General. Amado Alonso (trad.) Madrid: Alianza, 1990, 2.a reimpr.

Dioses y Hombres de Huarochirí. Narración quechua recogida por Francisco de Ávila [i 1598?]. Edición bilingüe. José María Arguedas (trad.) Lima: Museo Nacional de Historia/Instituto de Estudios Peruanos, 1966.

Forgues, RolAND (1989): «La escritura arguediana», en José María Arguedas: Del pensamiento dialéctico al pensamiento trágico. Lima, Horizonte, pp. 35-85.

FouCAult, Michel (1966): Las palabras y las cosas. Una arqueologia de las ciencias humanas. Elsa Cecilia Frost (trad.) Madrid: Siglo Veintiuno de España, 1997, 25." ed. (1. ${ }^{a}$ de España).

Jaime Ramírez, Helios (1997): El papel de la etnolingüística en traducción. Curso celebrado en la Universitat Jaume I de Castello, 9-11 abril.

LaCan, JacQues (1966): Escritos II. Tomás Segovia (trad.) México: Siglo Veintiuno, $1978,3 .^{a}$ ed.

Lévi-Strauss, Claude (1958): Antropología estructural. Eliseo Verón (trad.) Barcelona: Paidós, 1995, 2." reimpr.

- (1962): El pensamiento salvaje. Francisco González Aramburo (trad.) México: Fondo de Cultura Económica, 1972, 2. ${ }^{\text {a }}$ reimpr.

LIENHARD, MARTIN (1981): Cultura andina y forma novelesca. Zorros y danzantes en la última novela de Arguedas. Lima: Horizonte/Tarea, 1990, 2." ed. ampliada. Crítica literaria, núm. 8.

López García, Ángel. (1988): La Psicolingüística. Madrid: Síntesis, Colección Lingüística, nüm. 19.

Mounin, GEORGEs (1967): Historia de la lingüística. Desde los orígenes al siglo XX. Felisa Marcos (trad.) Madrid: Gredos, 1979, 3." reimpr. 
- (1972): La lingüística del siglo XX. Segundo Álvarez (trad.) Madrid: Gredos, 1984, 1. reimpr.

Paz, Octavio (1950): El laberinto de la soledad. Enrico Mario Santí (ed.) Madrid: Cátedra, 1995, 2. ${ }^{a}$ ed.

- (1974): El mono gramático. Barcelona: Círculo de Lectores, 1996.

Platón (s. f.): Cratilo o de la exactitud de las palabras. Francisco de P. Samaranch (trad.), en Obras completas. Madrid: Aguilar, 1972, 2. ed., pp. 497-552.

RAMA, ÁNGel (1982): Transculturación narrativa en América Latina. México: Siglo Veintiuno, 1987, 3. ${ }^{a} \mathrm{ed}$.

ROA BAStos, Augusto (1974): Yo el Supremo. Barcelona: RBA, 1993.

RoBINS, R.H. (1967): A short History of Linguistics. London/New York: Longman, 1990, 3rd. ed.

Rotaetxe Amusategui, Karmele (1990): Sociolingüística. Madrid: Síntesis, Colección Lingüística, núm. 13, 1. reimpr.

Rowe, William (1979): Mito e ideología en la obra de José María Arguedas. Lima: Instituto Nacional de Cultura. Cuadernos del INC, núm. 3.

WhITE, HAYDEN (1978): «Foucault decoded: Notes from underground», in Tropics of Discourse. Essays in Cultural Criticism. Baltimore and London: The Johns Hopkins University Press, 1992, 5th printing, pp. 230-60. 